\title{
Analisis Kinerja Protokol Routing AOMDV pada VANET dengan Serangan Rushing
}

\author{
RATNASIH, RISKI MUKTIARTO NUGROHO AJINEGORO, DOAN PERDANA
}

\author{
Universitas Telkom \\ Email : ratnasih@outlook.com
}

Received 21 Maret 2018 | Revised 23 April 2018 | Accepted 25 Mei 2018

\begin{abstract}
ABSTRAK
Vehicular Ad-hoc Network (VANET) adalah salah satu jaringan mobile Ad Hoc yang memiliki mobilitas tinggi serta topologi yang berubah - ubah secara konstan dalam waktu yang singkat. Sistem broadcast yang diterapkan pada VANET ketika pembentukan arsitektur infrastruktur bisa dijadikan peluang bagi penyerang node untuk melakukan serangan terhadap routing protocol. Rushing Attack adalah sebuah serangan jaringan dimana serangan ini melakukan duplikasi secara cepat dengan transmisi yang lebih tinggi untuk mengacaukan jaringan dan mendapatkan forward akses yang lebih dibandingkan dengan node yang lain. Sasaran utama dari penelitian ini yaitu untuk mengukur dampak dari serangan Rushing pada protocol routing AOMDV (Adhoc on Demand Multipath Distance Vector) menggunakan software NS-2. Nilai QoS yang didapatkan pada hasil penelitian ini tidak maksimal, karena attacker mengirimkan rushed routing packets (RREQ or RREP) yang mempengaruhi routing tabel eksisting dan mengacaukan proses pengiriman paket.
\end{abstract}

Kata kunci: VANET, Rushing Attack, AOMDV, NS-2

\begin{abstract}
Vehicular Ad-hoc Network (VANET) is kind of an Ad-Hoc mobile network that have high mobility and with changing topology constantly in a short time. The broadcast system that applied to the infrastructure architecture formation when VANET can be used as opportunities for penyerang nodes to perform attacks on the routing protocol. Rushing Attack is an attack on the network that the attacks quickly duplicating with higher transmission to disrupt the network and getting forward more access than the other node. The main target of this project is to measure how big the impact of the rushing attack on AOMDV(Adhoc on Demand Multipath Distance Vector) routing protocol using NS-2 software. On this project did not gets the maximum value for QoS because the attacker sent rushed routing packets (RREQ or RREP) that affect the routing table and disturb the delivery package.
\end{abstract}

Keywords: VANET, Rushing Attack, AOMDV, NS-2 


\section{PENDAhuluan}

Teknologi telekomunikasi semakin berkembang dengan cepat untuk meningkatkan mobilitas kerja dan memudahkan kegiatan manusia dalam berbagai aspek. Oleh karena itu dibutuhkan jenis jaringan yang dapat diakses oleh banyak pengguna atau peralatan komunikasi tanpa bergantung pada infrastruktur. VANET adalah salah satu subkelas dari MANET (Mobile $A d$ hoc Network) yang khusus digunakan sebagai teknologi jaringan mobile. VANET merupakan salah satu jaringan yang mempengaruhi Intelegent Transportation System untuk meningkatkan keamanan dan kenyamanan pengendara (Gadkari \& Sambre, 2012).

VANET adalah jenis jaringan ad hoc di mana kendaraan dan pinggir jalan unit adalah communivating node, memberikan satu sama lain dengan informasi, seperti peringatan keamanan dan informasi lalu lintas (Perdana \& Sari, 2015). VANET memiliki karakteristik yang sedikit berbeda dari MANET, dengan demikian mobilitas model dalam MANET tidak selalu sesuai ketika digunakan untuk VANET (Perdana, Munandi, \& Manurung, 2017). Perbedaan utama antara VANET dengan MANET yaitu VANET adalah jaringan ad-hoc yang diimplementasikan pada kendaraan sebagai node yang bertindak sebagai router yang bergerak dengan mobilitas yang sangat tinggi, sehingga menyebabkan topologi pada VANET berubah ubah dalam jangka waktu yang singkat. VANET memungkinkan komunikasi antar kendaraan saling terhubung dan bertukar informasi satu sama lain melalui Vehicle to Vehicle (V2V), dan kendaraan berkomunikasi melewati infrastruktur jaringan melalui Vehicle to Infrastruktur (V2I) (Raw \& Das, 2011).

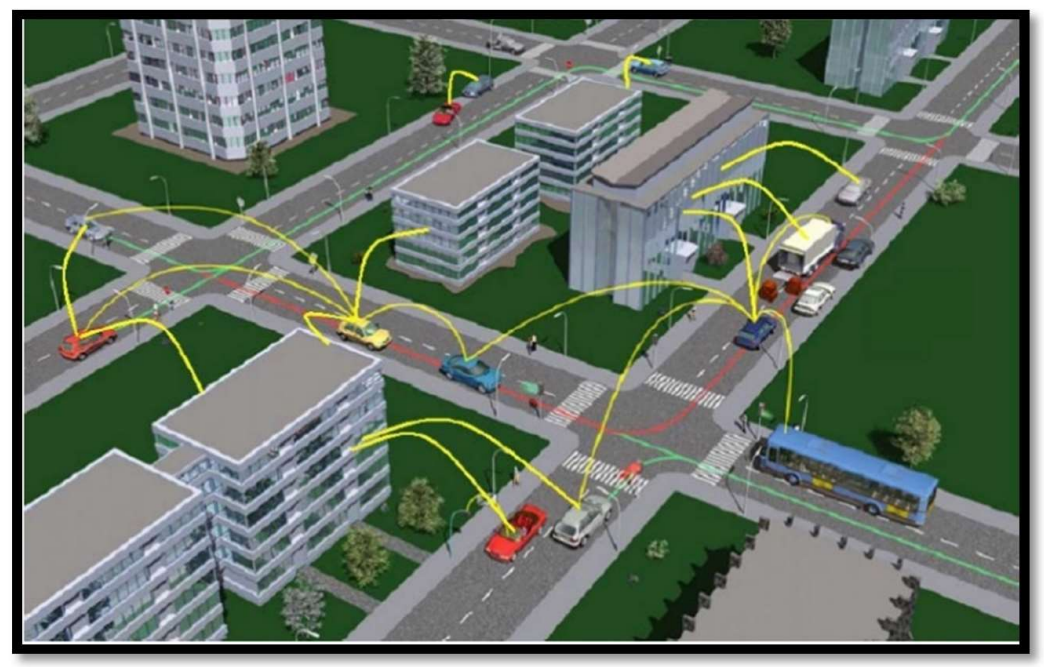

Gambar 1. Overview VANET (Raw \& Das, 2011)

Pada dasarnya, VANET adalah jaringan ad-hoc yang tidak memiliki pengetahuan tentang topologi jaringan yang berada disekitar mereka. Setiap node hanya mengirimkan pengumuman kehadirannya dan menyadari keberadaan node tetangganya secara otomatis dengan menggunakan broadcasting packets. Untuk menemukan node tetangga yang terdekat, dibutuhkan protokol routing. Selain itu, VANET merupakan jaringan terbuka dan media komunikasi tanpa mekanisme keamanan. Sehingga, ada banyak node serangan berbahaya pada VANET. Serangan rushing merupakan sebuah serangan jaringan dimana serangan ini melakukan duplikasi secara cepat dengan transmisi yang lebih tinggi untuk mengacaukan jaringan dan mendapatkan forward akses yang lebih jika dibandingkan dengan node yang lain (Wafta, 2010). Maka, perlu dilakukan analisis mengenai dampak 
Ratnasih, dkk

dari serangan berbahaya ini pada protocol routing VANET. Analisis ini dilakukan untuk menguji nilai penurunan performansi dari QoS protocol AOMDV dengan adanya serangan rushing menggunakan skema perubahan jumlah node penyerang dan perubahan kecepatan node pada VANET.

\section{METODOLOGI PENELITIAN}

\subsection{Routing Protocol Pada VANET}

Protokol merupakan sebuah aturan yang bertugas mengatur setiap device untuk saling bertukar informasi melalui sebuah media jaringan, sedangkan routing merupakan sebuah proses pemindahan informasi dari pengirim ke penerima melalui sebuah jaringan. Sehingga protokol routing sangat dibutuhkan untuk mengirimkan sebuah paket data dari node pengirim ke node penerima, dengan melewati beberapa node penghubung (intermediate node), dimana protokol routing bertugas untuk mencari rute terbaik dari link yang akan

dilalui. Pemilihan rute terbaik tersebut dipilih berdasarkan beberapa pertimbangan seperti bandwith link dan jaraknya. Selain itu, protokol routing juga bertugas untuk mengatur cara komunikasi dua node selama pertukaran informasi. Hal ini termasuk prosedur dalam membangun rute, keputusan dalam forwarding dan tindakan dalam menjaga rute atau memperbaiki routing yang gagal.

Pada umumnya protokol routing ad-hoc dikategorikan menjadi tiga bagian, yaitu flat routing, routing hirarki, dan posisi geografis yang dibantu routing. Pada flat routing terbagi menjadi dua bagian, yaitu table driven atau proaktif routing dan demand routing atau reaktif routing. Reaktif routing juga dikenal sebagai routing permintaan, karena mereka tidak menjaga informasi routing di node jaringan ketika tidak ada komunikasi. Jika node ingin mengirimkan paket ke node lain, maka protokol ini yang akan mencari rute permintaan serta menetapkan komunikasi untuk mengirimkan dan menerima paket-paket. AODV adalah routing protokol yang hanya me-request sebuah rute saat dibutuhkan (Prasetia, Perdana, \& Negara, 2018), begitu pula dengan AOMDV, maka keduanya merupakan salah satu contoh protokol routing reaktif.

AOMDV adalah protokol routing perkembangan dari protokol AODV. Jumlah rute yang ditemukan setiap kali melakukan pencarian rute adalah perbedaan utama antara AODV dan AOMDV. AOMDV dan AODV menggunakan sebuah sistem sequence number untuk memastikan bahwa rute yang dihasilkan adalah loop-free serta memiliki informasi routing yang paling terbaru. Pada AOMDV dan AODV, terdapat tiga buah pesan utama yang digunakan untuk proses pembentukan jalur routing dan pemeliharaan jalur routing yaitu : route request (RREQ), route replay (RREP) dan route error (RERR) (Awerbuch \& Mishra, 2014). Namun AOMDV pada saat pencarian rute tidak seperti AODV yang hanya memilih satu RREP, tetapi pada AOMDV setiap RREP akan dipertimbangkan oleh node asal sehingga beberapa path bisa ditemukan dalam satu pencarian rute. Dengan demikian, jika terjadi kegagalan rute pada saat perjalanan maka dapat dialihkan kerute yang lain. 


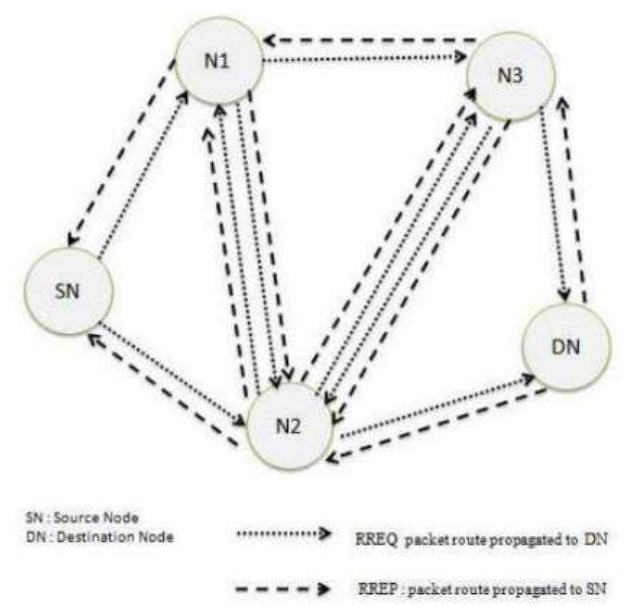

Gambar 2. Proses Propagasi RREQ dan RREP Pada AOMDV (Dubey, 2014)

Gambar 3 memperlihatkan langkah langkah protokol AOMDV untuk melakukan pencarian rute dan pemeliharaan rute. SN akan membanjiri jaringan dengan paket RREQ ketika ingin melakukan komunikasi dengan node tujuan sehingga node lain akan mendapatkan beberapa salinan dari RREQ yang sama. Selanjutnya, semua Salinan tersebut diperiksa untuk membuat rute alternatif, namun pemeliharaan rute hanya dibuat menggunakan RREQ yang dapat mempertahankan loop-freedom dan disjointness mulai dari node asal. Ketika intermediate node menerima rute pemeliharaan melalui salinan RREQ, node ini akan memeriksa apakah ada satu atau lebih forward paths ke node tujuan yang valid. Jika ada, node ini akan membuat paket RREP dan mengirim kembali melalui rute pemeliharaan ke node sumber.

Saat node tujuan menerima salinan RREQ, node tersebut juga membuat rute pemeliharaan dengan cara yang sama dengan yang dilakukan oleh intermediate node. Namun, RREP yang dibuat oleh node tujuan dibuat dengan aturan yang lebih "longgar". Maksudnya adalah node tujuan bisa mengirim RREP melalui rute pemeliharaan yang loop-free tanpa harus disjoint. Hal ini dilakukan untuk mencegah "route cutoff" atau rute yang dihapus karena terjadi suppressing atau ketika sebuah node harus memilih satu dari dua atau lebih path. Route maintenance pada AOMDV adalah penambahan sederhana pada AODV. Sama seperti AODV, AOMDV menggunakan paket RERR. Sebuah node akan membuat atau meneruskan paket RERR untuk node tujuan saat path terakhir ke node tujuan rusak. AOMDV juga melakukan optimalisasi untuk menyelamatkan paket yang sedang dikomunikasikan melalui link yang rusak dengan meneruskan ulang paket tersebut melalui jalur alternatif (Anisia, Munandi, \& Negara, 2016).

\subsection{Rushing Attack}

Rushing attack adalah serangan zero delay dan lebih efektif ketika penyerang dekat dengan node sumber atau tujuan. Protokol routing berdasarkan permintaan seperti AOMDV lebih rentan terhadap serangan ini, karena setiap kali sumber node membanjiri rute permintaan paket dalam jaringan, node musuh menerima rute permintaan paket dan mengirim tanpa hop_count setiap update dan delay dalam jaringan. Setiap kali node sah menerima paketpaket permintaan original source, lalu mereka di dropped. Setelah itu ketika node sah telah menerima paket dari penyerang dan treat saat ini menerima paket seperti paket duplikasi. Dengan demikian, musuh yang disertakan dalam rute akan aktif dan mengganggu fasa penerusan data. Rushing attack dapat mengambil tempat di sumber atau di sisi tujuan atau di tengah. 
Berikut adalah kondisi rushing attack tidak termasuk node aktif :

1. Ketika sumber dan tujuan memiliki komunikasi langsung.

2. Ketika sumber dan tujuan memiliki rute lebih baik daripada rushing attack.

3. Ketika node penyerang dekat dengan node sumber atau tujuan.

Protokol routing AOMDV hanya menganggap penerima pertama paket routing sebagai route discovery. Rushing attacker mengirimkan rushed routing packets (RREQ atau RREP) lebih cepat kepada node target dibandingkan kepada node pengirim sah lainnya. Rushing attacker mengirimkan routing paket rushed lebih cepat dengan mengabaikan MAC layer dan/atau delay layer routing, atau dengan menggunakan jangkauan transmisi yang lebih tinggi.

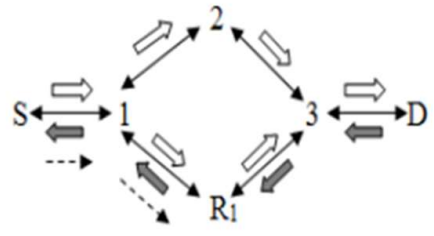

(a)

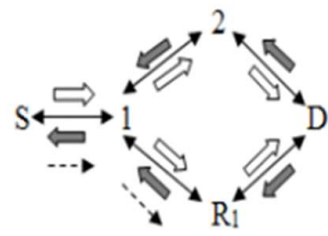

(b)

\begin{tabular}{|l|l|}
\hline S: Source & $\Rightarrow$ RREQ \\
D:Destination & $\Leftrightarrow$ RREP \\
$\longleftrightarrow$ Bidirectional Wireless Link & $\ldots$ Data \\
\hline
\end{tabular}

Gambar 3. Rushing Attacker Menolak MAC/Routing Layer Delay (Hazra \& Setua, 2012)

Pada Gambar 3 (a), node R1 merupakan rushing attacker yang mengirimkan rushed RREQ lebih cepat ke target node 3, dibandingkan dengan node 2, dengan mengabaikan delay. Node 3 membuang RREQ yang terakhir kali diterima dan diteruskan pada node 2, dan meneruskan RREQ rushed ke destinasi D yang pertama kali diterima R1. Oleh sebab itu, D membalas dengan RREP menuju sumber melalui R1. Hasilnya, sumber akan meneruskan seluruh paket data menuju R1. Pada Gambar 3 (b), node R1 merupakan rushing attacker yang mengirimkan rushed RREP lebih cepat ke target node 1, dibandingkan dengan node 2, dengan mengabaikan delay. Node 1 membuang RREP yang terakhir kali diterima dan diteruskan pada node 2, dan meneruskan RREP rushed ke destinasi S yang pertama kali diterima R1. Hasilnya, S meneruskan seluruh paket data menuju R1 dan R1 menggunakan data-data tersebut.

Tipe lainnya dari rushing attacker adalah mengirimkan rushed routing packets menuju node target yang menggunakan jangkauan transmisi yang lebih tinggi. Jangkauan transmisi yang tinggi disini yaitu memiliki minimal range dua kali dari range normal. Pada Gambar 4 (a), node R2 merupakan rushing attacker yang mengirimkan rushed RREQ kepada target node 4 lebih cepat dibandingkan ke node 2 . Node 4 membuang RREP yang sampai ke node 2 melalui node 3 dan meneruskan rushed RREQ ke destinasi D yang pertama kali diterima node R2. Oleh sebab itu, D membalas dengan RREP menuju sumber melalui R2. Selama R2 menggunakan jangkauan transmisi yang tinggi, link wireless antara node 4 dan R2 bukanlah link bidirectional. Ketika D meneruskan RREP mencapai node 4, maka tidak dapat diteruskan ke R2 karena jangkauan transmisi node 4 yang lebih pendek. Hasilnya, node S tidak bisa mendapatkan RREP dan tidak ada route yang akan disiapkan antara S dan D. 


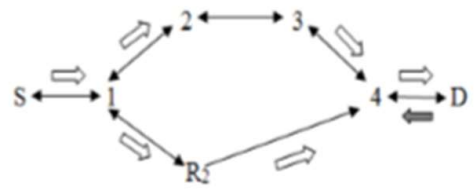

(a)

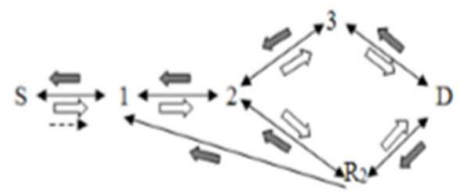

(b)

\begin{tabular}{|l|l|l|}
\hline S: Source & $\longleftrightarrow$ Bidirectional Wireless Link & $\Rightarrow$ RREQ \\
D: Destination & $\longrightarrow$ Unidirectional Wireless Link & $\Leftrightarrow$ RREP \\
& & $\cdots$ Data \\
\hline
\end{tabular}

Gambar 4. Rushing Attacker Menggunakan Range Transmisi Tinggi (Hazra \& Setua, 2012)

Pada Gambar 4 (b), node R2 merupakan rushing attacker yang mengirimkan rushed RREP menggunakan jangkauan transmisi yang tinggi. R2 mengirimkan rushed RREP ke target node 1 lebih cepat daripada ke node 3 . Node 1 membuang RREP yang mencapai node 3 melalui node 2 yang terakhir diterima dan meneruskan rushed RREP ke tujuan S yang pertama kali diterima oleh R2. Oleh sebab itu, S mengirimkan seluruh data ke R2 menuju D. karena R2 menggunakan jangakauan transmisi yang tinggi, link wireless antara R2 dan node 1 bukanlah link bidireksional. Ketika S meneruskan RREP mencapai node 1, RREP tersebut tidak dapat diteruskan ke R2 karena jagkauan transmisi node 1 yang lebih pendek. Hasilnya, node D tidak akan mendapatkan data apapun dari S (Hazra \& Setua, 2012).

\subsection{Skenario Simulasi}

Model mobilitas yang akan digunakan adalah freeway based on map. Skenario simulasi yang digunakan adalah jaringan VANET dengan protokol routing AOMDV, dengan skenario sebagai berikut:

1. Perbedaan jumlah node dengan range $15,20,25,30,35$, dan 40 node dengan node malicious sebanyak 3 buah node.

2. Perbedaan jumlah node malicious dengan range 1, 2, 3, 4, 5 dan 6 node dengan menggunakan jumlah node yang konstan sebanyak 30 buah node.

3. Perbedaan kecepatan mobilitas node dengan kecepatan $70 \mathrm{~km} / \mathrm{jam}, 80 \mathrm{~km} / \mathrm{jam}, 90$ $\mathrm{km} / \mathrm{jam}, 100 \mathrm{~km} / \mathrm{jam}, 110 \mathrm{~km} / \mathrm{jam}$, dan $120 \mathrm{~km} / \mathrm{jam}$, dengan node malicious sebanyak 3 node dan jumlah total node sebanyak 30 node yang konstan.

4. Perbedaan jumlah node malicious sebanyak 1, 2, 3, 4, 5, dan 6 node dengan kecepatan yang tetap yaitu $90 \mathrm{~km} / \mathrm{jam}$.

Adapun beberapa parameter yang digunakan dalam skenario simulasi pada penelitian ini adalah sebagai berikut:

Tabel 1. Parameter Simulasi

\begin{tabular}{|l|l|}
\hline \multicolumn{1}{|c|}{ Parameter } & \multicolumn{1}{c|}{ Nilai } \\
\hline Jumlah Node & $15,20,25,30,35,40$ Node \\
\hline Node Malicious & $1,2,3,4,5,6$ Node \\
\hline Kecepatan & $70,80,90,100,110,120 \mathrm{~km} / \mathrm{jam}$ \\
\hline Routing Protocol & AOMDV \\
\hline Mac Type & IEEE $802.11 \mathrm{p}$ \\
\hline Attack & Rushing attack \\
\hline Waktu Simulasi & 350 detik \\
\hline
\end{tabular}




\subsection{Parameter Uji Perfomansi}

Parameter uji performansi merupakan salah satu usaha untuk mengetahui kinerja jaringan oleh performansi routing protocol. Parameter uji performansi identik dengan Quality of Service (QoS). Dalam penelitian ini, digunakan parameter QoS, yaitu:

1. Packet Delay Ratio (PDR)

Packet Delay Ratio merupakan hasil perbandingan antara jumlah paket data yang berhasil dikirim ke node tujuan dengan jumlah paket data yang dikirim dari node sumber. Semakin tinggi nilai PDR, maka performansi protokol lebih baik. Rumus perhitungan PDR yaitu:

$$
\text { Packet Delay Ratio }=\left(\sum \operatorname{Pr}\right) /\left(\sum P s\right) \times 100 \%
$$

Dimana $\operatorname{Pr}$ adalah paket yang diterima, dan $P s$ adalah paket yang dikirim.

2. Rata-rata End-to-End-Delay

Rata-rata End-to-End-Delay (EED) sebuah jumlah waktu total yang dibutuhkan oleh paket data yang dikirim dari ujung sumber ke tujuan akhir. Untuk parameter ini, semakin kecil waktu yang digunakan, maka semakin baik performansinya [16]. Rumus perhitungan rata-rata EED yaitu:

$$
E E D=\sum(\text { waktu terima }- \text { waktu kirim })
$$

\section{Throughput}

Throughput merupakan jumlah bit yang berhasil diterima dalam selang waktu tertentu. Semakin tinggi nilai throughput, maka performansi protokolnya semakin baik juga. Rumus perhitungan throughput yaitu:

$$
\text { Throughput }=\frac{\text { Jumlah data yang diterima }}{\text { Waktu pengiriman data }}
$$

\section{HASIL DAN PEMBAHASAN}

\subsection{Analisa Hasil Simulasi}

\subsubsection{Hasil Simulasi Menggunakan Perubahan Jumlah Node}

Berikut ini adalah hasil pengukuran menggunakan routing protocol AOMDV dengan perubahan jumlah node dari 15, 20, 25, 30, 35, dan 40 node. Lalu 3 node penyerang dengan membandingkan hasil pengukuran VANET dengan serangan rushing dan VANET tanpa serangan rushing. Gambar 5 memperlihatkan bahwa grafik AOMDV terhadap serangan rushing memiliki nilai PDR yang kurang baik dibandingkan dengan nilai PDR tanpa adanya serangan rushing. Nilai PDR naik secara perlahan mulai dari jumlah node 15 buah sampai jumlah node sebanyak 30 buah, lalu mengalami penurunan pada node 35 yang selanjutnya mengalami kenaikan pada node 40. 


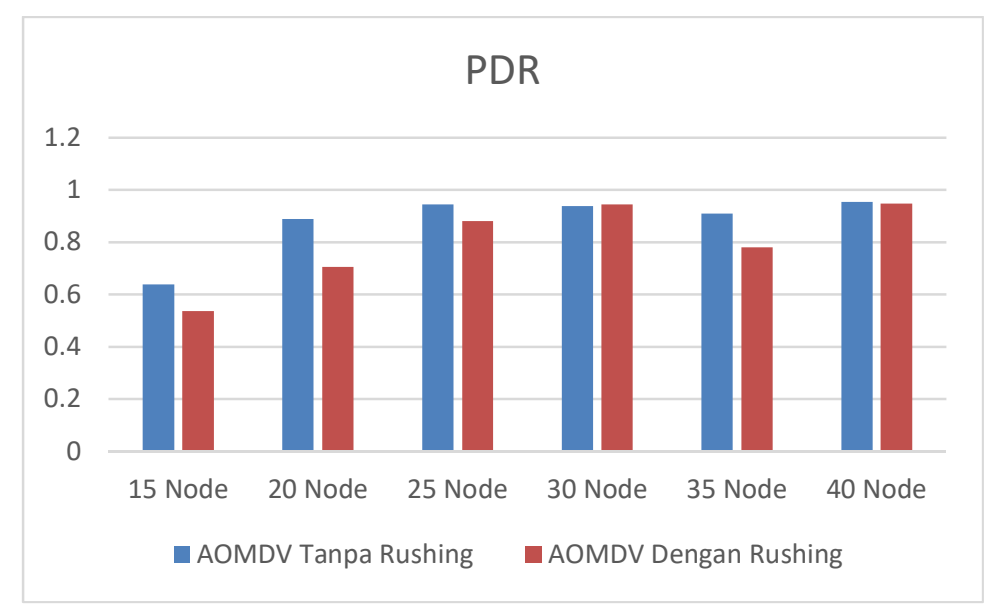

Gambar 5. Hasil PDR dengan Perubahan Jumlah Node

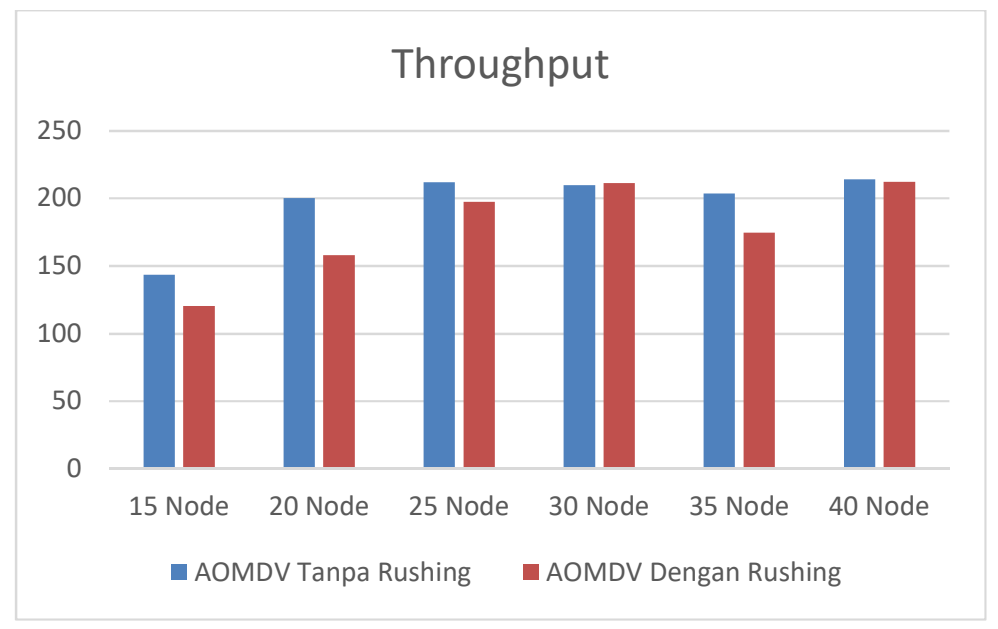

Gambar 6. Hasil Throughput dengan Perubahan Jumlah Node

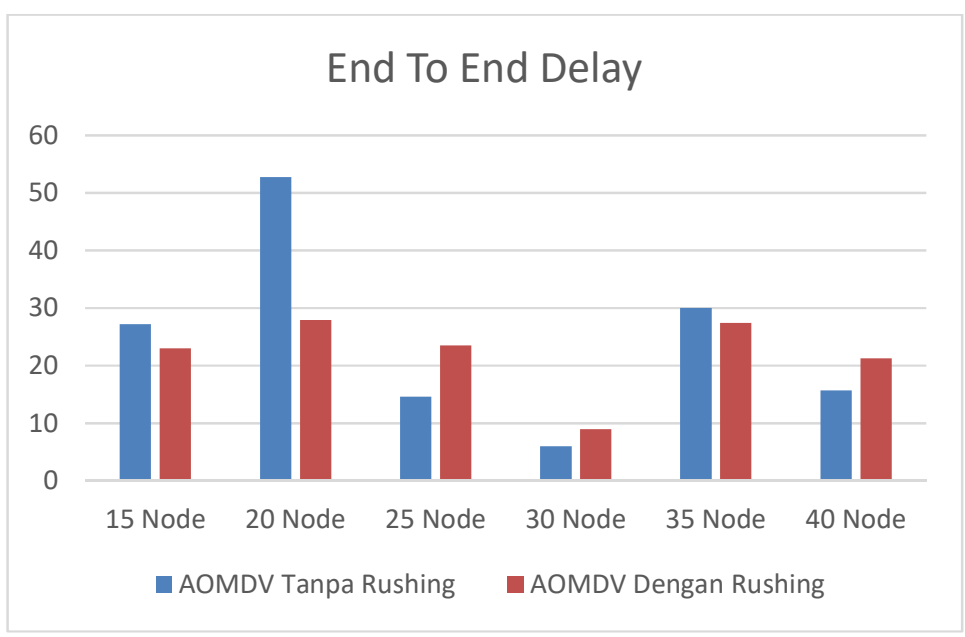

Gambar 7. Hasil End-to-End-Delay dengan Perubahan Jumlah Node 
Gambar 6 menunjukan bahwa grafik AOMDV terhadap serangan rushing memiliki nilai througput yang kurang baik dibandingkan dengan nilai throughput tanpa adanya serangan rushing. Nilai throughput naik pada jumlah node 25 buah dan mengalami penurunan secara perlahan pada node 30 dan 35 yang selanjutnya mengalami kenaikan pada node 40. Gambar 7 memperlihatkan bahwa grafik AOMDV terhadap serangan rushing memiliki nilai End-toEnd-Delay yang fluktuatif serta memiliki nilai yang lebih besar daripada nilai End-to-EndDelay tanpa adanya serangan rushing.

\subsubsection{Hasil Simulasi Menggunakan Perubahan Jumlah Node Penyerang}

Berikut ini adalah hasil pengukuran menggunakan protokol routing AOMDV dengan perubahan jumlah node malicious sebanyak 1, 2, 3, 4, 5 dan 6 node dengan jumlah node sebanyak 30 buah node. Terlihat pada Gambar 8 bahwa grafik AOMDV dengan skema rushing attack terhadap perubahan jumlah node malicious memiliki nilai PDR yang fluktuatif. Pada jumlah 3 node penyerang, nilai PDR naik dari 0.9386 menuju 0.9446 lalu turun kembali pada jumlah node 4.

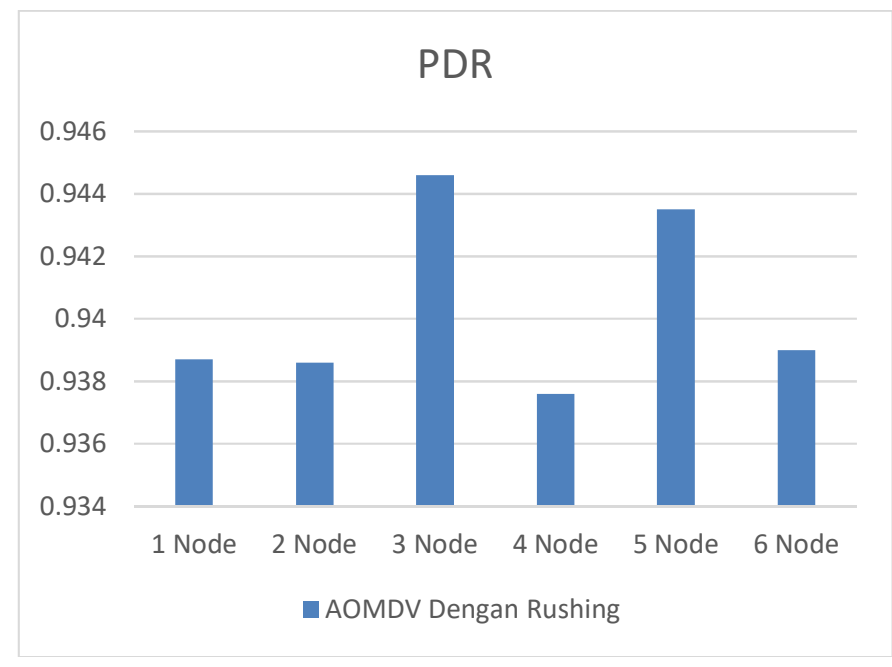

Gambar 8. Hasil PDR dengan Perubahan Jumlah Penyerang

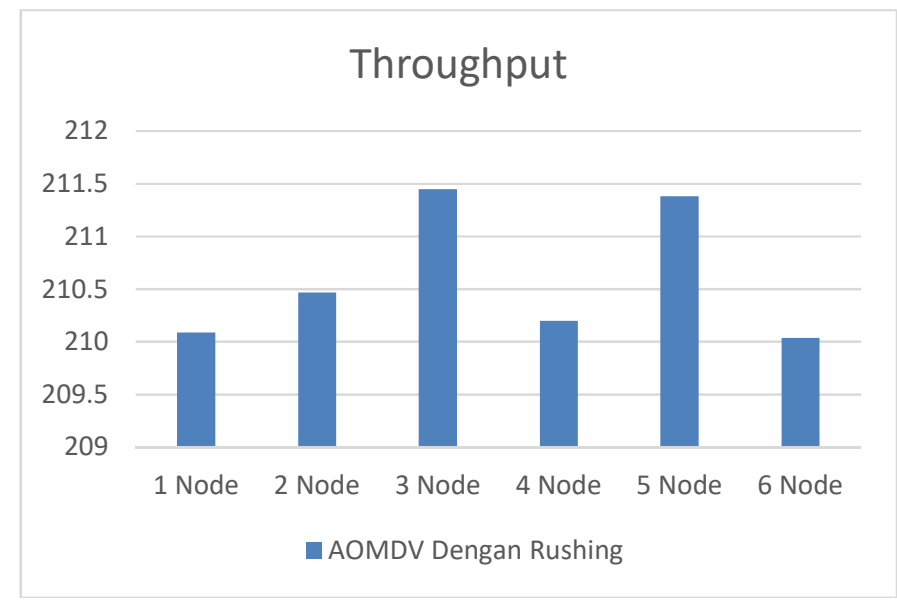

Gambar 9. Hasil Throughput dengan Perubahan Jumlah Penyerang 


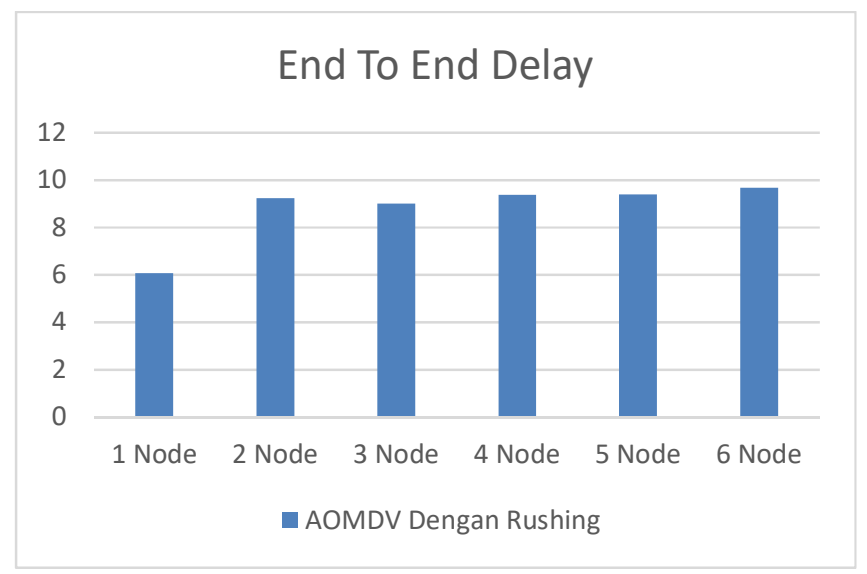

Gambar 10. Hasil End-to-End-Delay dengan Perubahan Jumlah Penyerang

Gambar 9 memperlihatkan bahwa grafik AOMDV dengan skema serangan rushing terhadap perubahan jumlah node penyerang memiliki nilai throughput yang fluktuatif. Pada jumlah 3 node penyerang, nilai throughput naik dari 210,47 kbps menuju 211,45 kbps, lalu mengalami fluktuatif bergantian mulai dari node 2 sampai node 6. Terlihat pada Gambar 10 bahwa grafik AOMDV dengan skema serangan rushing terhadap perubahan jumlah node memiliki nilai End-to-End-Delay yang fluktuatif pada node 1 sampai dengan node 3, kemudian mengalami kenaikan perlahan dimulai dari node 4 sampai node 6 dengan rata rata $9 \mathrm{~ms}$.

\subsubsection{Hasil Simulasi Menggunakan Perubahan Kecepatan Node}

Berikut ini adalah hasil pengukuran menggunakan protokol routing AOMDV dengan perubahan kecepatan node dengan variasi kecepatan $70 \mathrm{~km} / \mathrm{jam}, 80 \mathrm{~km} / \mathrm{jam}, 90 \mathrm{~km} / \mathrm{jam}$, $100 \mathrm{~km} / \mathrm{jam}, 110 \mathrm{~km} / \mathrm{jam}$, dan $120 \mathrm{~km} / \mathrm{jam}$. Skenario tersebut dilengkapi dengan total jumlah node sebanyak 30 node yang berisikan 3 node malicious. Gambar 11 menunjukan nilai PDR yang fluktuatif. Pada saat $70 \mathrm{~km} / \mathrm{jam}$, nilai PDR semakin menurun, namun naik secara perlahan kembali ketika $100 \mathrm{~km} / \mathrm{jam}$ sampai $120 \mathrm{~km} / \mathrm{jam}$.

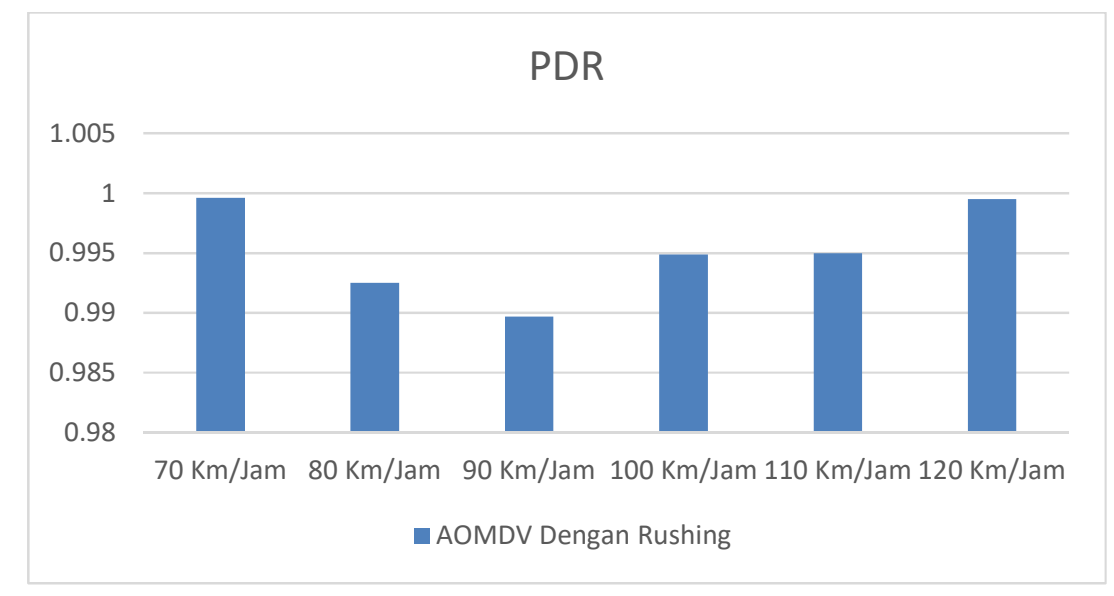

Gambar 11. Hasil PDR dengan Perubahan Kecepatan Node 
Ratnasih, dkk

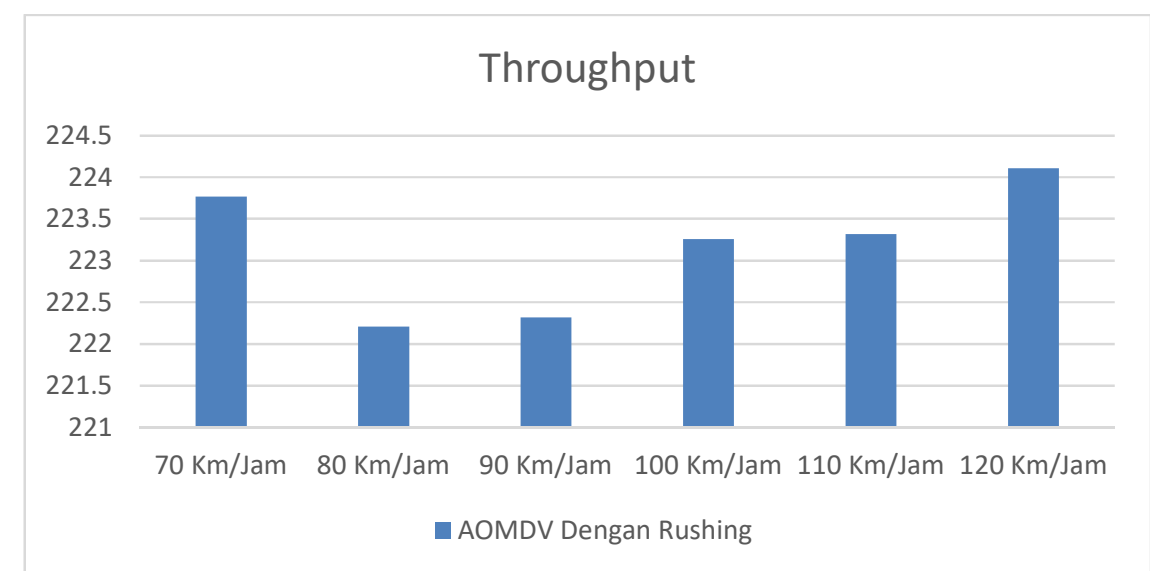

Gambar 12. Hasil Throughput dengan Perubahan Kecepatan Node

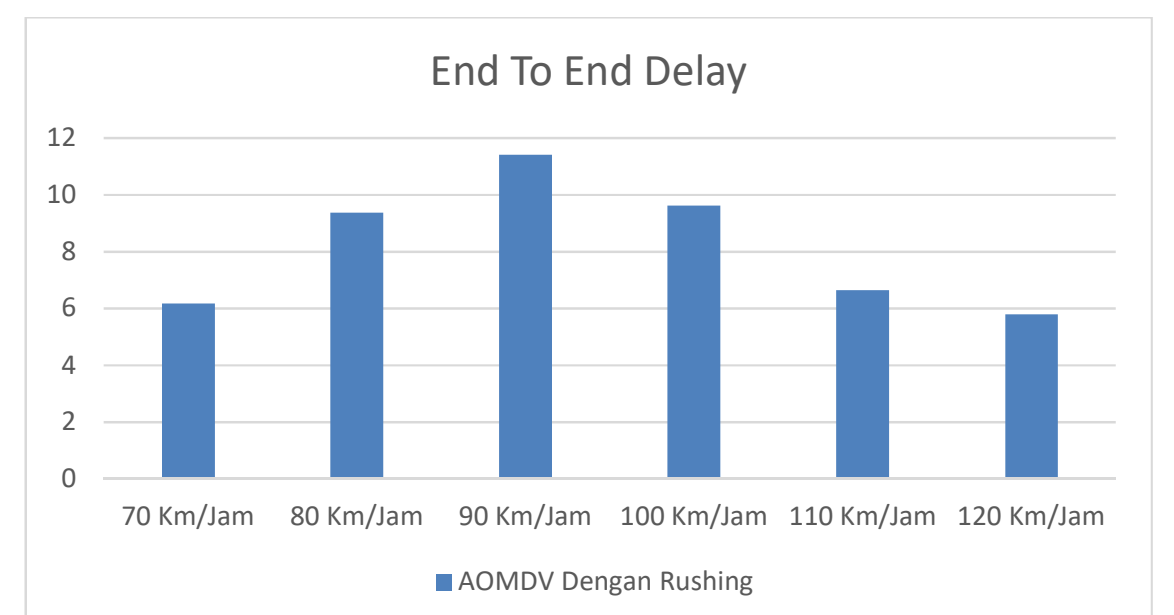

Gambar 13. Hasil End-To-End-Delay dengan Perubahan Kecepatan Node

Gambar 12 menunjukkan hasil dari throughput bergerak secara fluktuatif. Nilai throughput tertinggi ada pada saat kecepatan $120 \mathrm{~km} / \mathrm{jam}$ dan nilai terendah ada pada saat $80 \mathrm{~km} / \mathrm{jam}$. Gambar 13 menunjukkan hasil dari End-to-End Delay yang bergerak secara fluktuatif. Nilai terendah berada pada saat kecepatan $70 \mathrm{~km} / \mathrm{jam}$ dan paling tinggi ada di kecepatan 90 $\mathrm{km} / \mathrm{jam}$.

\section{KESIMPULAN}

Penelitian mengenai kinerja jaringan VANET dengan skema serangan rushing attack ini menghasilkan kesimpulan sebagai berikut:

1. Pada kondisi tanpa adanya serangan rushing, performansi QOS AOMDV dengan skenario perubahan jumlah node memiliki nilai performansi yang baik dikarenakan ketika proses pengiriman data tidak mengalami gangguan.

2. Pada kondisi dengan adanya serangan rushing, performansi QOS AOMDV pada skenario perubahan node memilki nilai yang kurang baik dibandingkan dengan tanpa adanya serangan. Hal ini dikarenakan adanya gangguan yang disebabkan oleh node penyerang yang menganggu proses routing. Dengan begitu, didapatkan nilai rata- 
rata throughput sebesar $204.5 \mathrm{kbps}$, lalu nilai PDR sebesar $0.944 \%$, serta nilai endto-end delay sebesar $42.37 \mathrm{~ms}$.

3. Pada kondisi dengan adanya serangan rushing, performansi QOS AOMDV pada skenario perubahan jumlah node penyerang memiliki nilai yang fluktuatif, dimana nilai performansi QOS berada pada titik terendah ketika kondisi jaringan memiliki 3 node penyerang. Hal ini dipengaruhi oleh banyak faktor seperti posisi, mobilitas dan traffic yang ada pada jaringan tersebut.

4. Pada kondisi dengan perubahan kecepatan, performansi QOS AOMV memiliki nilai yang fluktuatif. Hal ini terjadi karena faktor jumlah node malicious, mobilitas, serta traffic yang ada pada jaringan AOMDV tersebut.n

\section{DAFTAR RUJUKAN}

Gadkari, M. Y., \& Sambre, N. B. (2012). VANET : Routing Protocols, Security Issues and Simulation Tools. IOSR Journal of Computer Engineering (IOSRJCE), 28-38.

Perdana , D., \& Sari, R. F. (2015). Performance Evaluation of Corrupted Signal Caused by Random Way Point and Gauss Markov Mobility Model on IEEE 1609.4 Standards. IEEE.

Perdana, D., Munandi, R., \& Manurung, R. C. (2017). Performance Evaluation of GaussMarkov Mobility Model in Hybrid LTE-VANET Networks. TELKOMNIKA, 606-621.

Raw, R. S., \& Das, S. (2011). Performance Comaparison of Posistion-based Routing Protocols in Vehicle-to-Vehicle (V2V) Communication. International Journal of Engineering Science and Technology (IJEST).

Wafta, M. (2010). Advances in Vehicular Ad-Hoc Networks: Developments and Challenges. Hershey: Information Science Reference.

Prasetia, D. R., Perdana, D., \& Negara, M. R. (2018). Analisis Kinerja GPSR dan AODV pada VANET dengan Skema Pengimbangan Beban Trafik. Jurnal ELKOMIKA.

Awerbuch, B., \& Mishra, A. (2014). Ad Hoc On Demand Distance Vector (AODV) Routing Protocol. Departement of Computer Science.

Dubey, S. (2014). Implementation of AOMDV, OLSR \& ZRP Protocol for Analysis of Performance Matrices in VANET Scenario. IJESRT, 3.

Anisia, R., Munandi, R., \& Negara, R. M. (2016). Simulasi Dan Analisis Performansi Protokol Routing OLSR DAN AOMDV Pada Jaringan Vehicular Ad-Hoc Network (VANET). Jurnal Nasional Teknik Elektro, 5.

Hazra, S., \& Setua, S. K. (2012). Rushing Attack Defending Context Aware Trusted AODV in Ad-Hoc Network. International Journal of Security, Privacy and Trust Management ( IJSPTM). 